\title{
Walkability and its association with prevalent and incident diabetes among adults in different regions of Germany: results of pooled data from five German cohorts
}

Nadja Kartschmit ${ }^{1,2}$, Robynne Sutcliffe ${ }^{3}$, Mark Patrick Sheldon ${ }^{4}$, Susanne Moebus ${ }^{3}$, Karin Halina Greiser ${ }^{1,5}$, Saskia Hartwig ${ }^{1,2}$, Detlef Thürkow ${ }^{6}$, Ulrike Stentzel ${ }^{7}$, Neeltje van den Berg ${ }^{7}$, Kathrin Wolf ${ }^{2,8}$, Werner Maier ${ }^{2,9}$, Annette Peters ${ }^{2,8}$, Salman Ahmed ${ }^{3}$, Corinna Köhnke ${ }^{10}$, Rafael Mikolajczyk ${ }^{1}$, Andreas Wienke ${ }^{1}$, Alexander Kluttig ${ }^{1,2^{*}}$ (D) and Gavin Rudge ${ }^{4}$

\begin{abstract}
Background: Highly walkable neighbourhoods may increase transport-related and leisure-time physical activity and thus decrease the risk for obesity and obesity-related diseases, such as type 2 diabetes (T2D).

Methods: We investigated the association between walkability and prevalent/incident T2D in a pooled sample from five German cohorts. Three walkability measures were assigned to participant's addresses: number of transit stations, points of interest, and impedance (restrictions to walking due to absence of intersections and physical barriers) within $640 \mathrm{~m}$. We estimated associations between walkability and prevalent/incident T2D with modified Poisson regressions and adjusted for education, sex, age at baseline, and cohort.

Results: Of the baseline 16,008 participants, 1256 participants had prevalent T2D. Participants free from T2D at baseline were followed over a mean of 9.2 years (SD: 3.5, minimum: 1.6, maximum: 14.8 years). Of these, 1032 participants developed T2D. The three walkability measures were not associated with T2D. The estimates pointed toward a zero effect or were within 7\% relative risk increase per 1 standard deviation with 95\% confidence intervals including 1.
\end{abstract}

Conclusion: In the studied German settings, walkability differences might not explain differences in T2D. Keywords: Built environment, Walkability, Diabetes, Cardio-metabolic risk factors, Epidemiology

\footnotetext{
*Correspondence: alexander.kluttig@uk-halle.de

OpenStreetmap copyright statementOpenStreetMap is open data, licensed under the Open Data Commons Open Database License (ODbL) by the OpenStreetMap Foundation (OSMF).

'Institute of Medical Epidemiology, Biometrics and Informatics, Martin-Luther-University Halle-Wittenberg, Magdeburger Straße 8, 06112 Halle (Saale), Germany

${ }^{2}$ German Center for Diabetes Research (Deutsches Zentrum für Diabetesforschung DZD), Ingolstädter Landstraße 1, 85764 Neuherberg, Germany

Full list of author information is available at the end of the article
}

(c) The Author(s). 2020 Open Access This article is distributed under the terms of the Creative Commons Attribution 4.0 International License (http://creativecommons.org/licenses/by/4.0/), which permits unrestricted use, distribution, and reproduction in any medium, provided you give appropriate credit to the original author(s) and the source, provide a link to the Creative Commons license, and indicate if changes were made. The Creative Commons Public Domain Dedication waiver (http://creativecommons.org/publicdomain/zero/1.0/) applies to the data made available in this article, unless otherwise stated. 


\section{Background}

Unhealthy diet and physical inactivity are important risk factors for developing non-communicable diseases, such as type 2 diabetes (T2D) [1]. While the prevention of such diseases is still focused on individual health behaviours, there is currently an increasing interest in settingbased prevention initiatives [2-4]. There is evidence that improved neighbourhood walkability, as characteristic of the built environment, increases walking and cycling. Hence, walkability may be associated with a reduced risk of obesity and T2D via increased transport-related and leisure-time physical activity [5-12].

Existing research showing a positive relationship between higher walkability and lower risk of incident and prevalent T2D comes mainly from Australia and North America [12, 13]. Since the built environment in Europe differs from Australia and North America [14, 15], it is not clear whether this association also exists in European countries. However, so far, there is only one study from Sweden showing no effect of walkability on incident T2D [16]. Our previous pooled analysis of data from five German cohorts indicated a weak association between higher walkability and lower body mass index (BMI) [17].

Most previous studies categorized continuous walkability measures, which is problematic in terms of loss of power and difficulties in pooling estimates from different studies [18]. Furthermore, most studies used a walkability score and did not assess walkability measures separately. A score does not permit conclusions as to which walkability parameter contributes most to the association with T2D and hampers comparability between studies since many options exist on which parameters to include in an index and how to weight them $[19,20]$.

In the current study, we assessed the association between three walkability measures and T2D prevalence and incidence in the German population using data from five German cohort studies.

\section{Methods}

\section{Study population}

Data from five population-based cohort studies from different German areas were included: The Heinz Nixdorf Recall Study (HNR), the Dortmund Health Study (DHS), both conducted in Western Germany, the Cooperative Health Research in the Region of Augsburg (KORA) S4 Survey from the South of Germany, The Cardiovascular Disease Living and Ageing in the city of Halle (CARLA) Study, and the Study of Health in Pomerania (SHIP), the latter two from the Eastern area of Germany. A detailed description of the studies can be found elsewhere [21-27]. Baseline data of all studies were collected between 1997 and 2006. Baseline response ranged from 56 to $69 \%$. Except for the DHS cohort with only one follow-up examination, all other cohort studies conducted at least two follow-up examinations. The follow-up investigations took place between 2002 and 2016 with mean observation times ranging from 2.2 years to 13.6 years. Participation at follow-ups ranged between 53.5 and $76.6 \%$ (of all baseline participants).

The studies have been conducted according to the principles of the Declaration of Helsinki and have been approved by local ethics committees and written informed consent has been obtained.

In total, 17,453 participants were included in the pooled sample of the five cohort studies. Cross-sectional data from 16,008 and longitudinal data from 12,105 participants were available for analysing the association between the walkability measures and prevalent and incident $\mathrm{T} 2 \mathrm{D}$, respectively, after excluding participants with missing values for exposure, outcome, or covariates (Fig. 1).

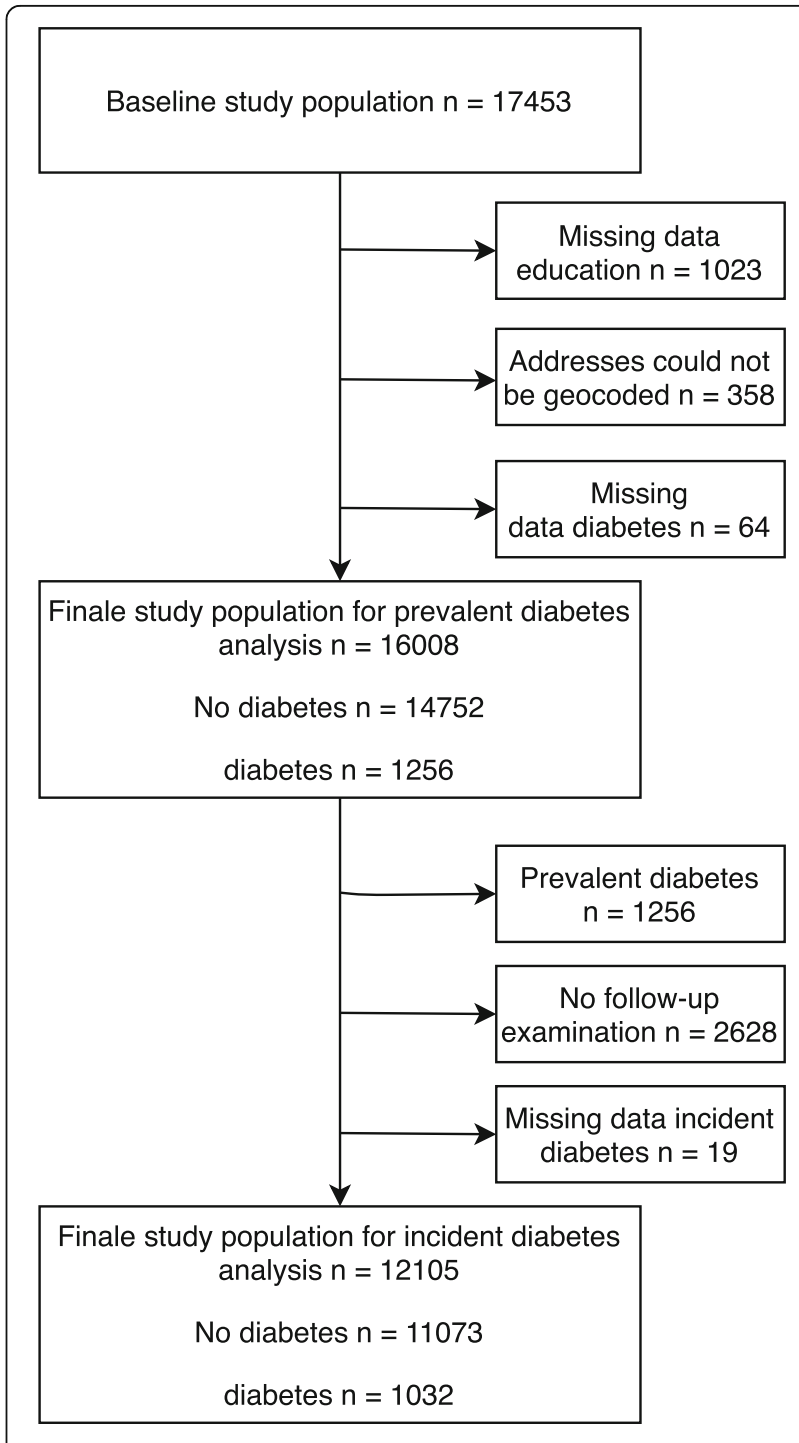

Fig. 1 Study population for prevalent and incident diabetes analysis 


\section{Walkability measures}

For deriving the walkability measures, the ArcGIS Geoinformation System in ESRI ArcMap Desktop versions 10.1 and 10.4 was used [Environmental Systems Research Institute (ESRI) 2012. 10.4, A.D.A.(ed.). Redlands]. We created a hexagonal sampling grid across each of the study regions covering the municipal boundary from which cohort participants had been recruited and a buffer of 1 kilometre beyond. Spatial interpolation will produce some spurious values at the edges of the areas it is applied to, so where possible it is performed on a larger area than needed and the resulting surface is trimmed to the extent of the study area. We picked 1000 $\mathrm{m}$ as the side length for the hexagons. The size of the hexagons was chosen pragmatically. We calculated hexagonal polygons depicting the area within a walking distance of $640 \mathrm{~m}$ for each of the hexagon's vertices and centroids by using paths, walkways, and roads (Fig. 2).

The transport networks (here transit stations) and points of interest (POI) for the cities were provided by OpenSteetMap (OSM) in 2016 and processed using ArcGIS to create the network dataset.

The three walkability measures derived were the following:

POI: For each vertice and centroid of the hexagons we calculated a polygon representing the area that could be reached within a walking distance of $640 \mathrm{~m}$, using roads, walkways and paths on the OSM network. There is very little research on what constitutes a short walk. The cut-off of $640 \mathrm{~m}$ was chosen because research carried out in London had proposed that the propensity to walk to access public transport declined rapidly after $640 \mathrm{~m} \mathrm{[28].} \mathrm{We} \mathrm{took} \mathrm{this} \mathrm{a} \mathrm{pragmatic}$ definition of a short, accessible walking distance. We defined POI using OSM. These POI were geo-located and subsequently given a descriptive tag and allocated to a category. For example, an entry may be tagged as 'bookshop' in the category 'shop', a cash dispenser may be tagged 'ATM' in the category 'amenity'. In each polygon we captured the number of points classified as a shop. In addition, we also selected some points classified as 'amenity' by undertaking a thorough review of the used tags. For each polygon, we thus summed up all shops and amenities tagged: ATM, bank, bar, Biergarten, café, fast food restaurant, pharmacy, pub, restaurant, and post office.

Transit stations: We followed exactly the same method to determine transit point availability as we did for POI. In the category 'highway' we captured all of the points tagged as 'bus stop'. In the category 'railway' we captured all points tagged as 'stop', 'tram stop', 'station', 'subway entrance' 'entrance' or 'platform' and in the category 'amenity' we captured all the points tagged as 'bus station', and 'ferry terminal'.

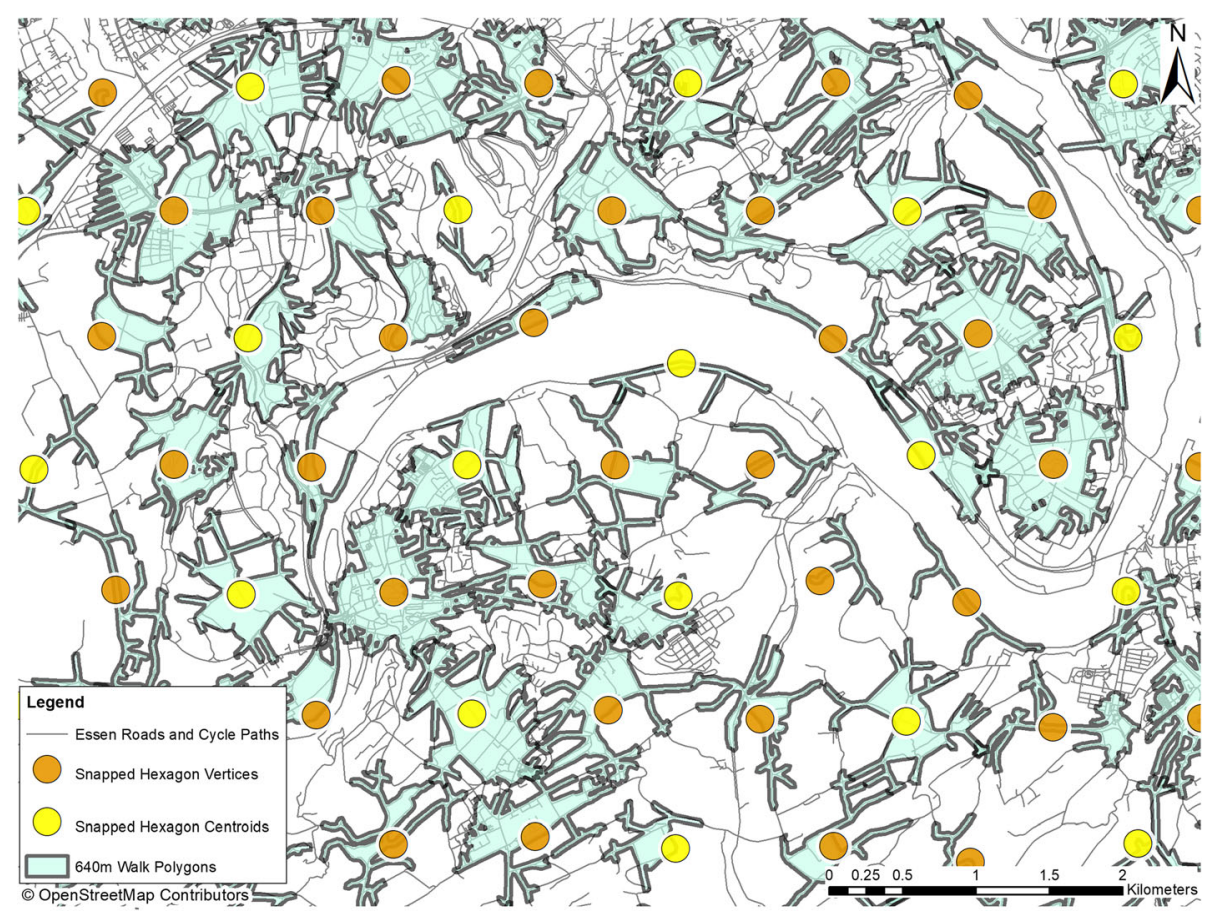

Fig. 2 Walk polygons with hexagon centroids and vertrices. The figure shows one area of Essen city (Heinz Nixdorf Recall study area). For creating the map, OpenStreetMap data was used. OpenStreetMap ${ }^{\oplus}$ is open data, licensed under the Open Data Commons Open Database License by the OpenStreetMap Foundation. Note to the journal: please use colours for print 
Impedance: Typically, connectivity is used as a proxy measure for impedance. Highly connected roads and paths will have many network notes (junctions of roads for example). Usually, the number of nodes of a road and path network in a given radius is counted to derive a simple metric of impedance. However, this approach does not capture physical barriers. Hence, we used an approach that would not only capture lack of intersections, but also physical barriers. From the centroid of each hexagon we calculated six journeys in six different directions: Northeast, Northwest, West, Southwest, Southeast, and East from the centre to each vertex of the hexagon. The six values vary according to ease of access in the various directions with higher values reflecting a lack of ease of walking in that direction. For example, if a point, which was $1000 \mathrm{~m}$ Euclidian distance away, was accessible by a journey of $2300 \mathrm{~m}$ this was 2.3 times larger than the Euclidian distance. A comparable $1000 \mathrm{~m}$ Euclidian distance that can be walked in $1050 \mathrm{~m}$ clearly has fewer barriers.

Each of the metrics was interpolated between the points to construct a surface. We used Kriging to interpolate values between the hexagonal points. Kriging estimates values between points of known values on a plane using a Gaussian regression process and is a widely used method in spatial modelling.

We intersected all created surfaces with the baseline residential addresses of the cohort's participants. All walkability surfaces were created in 2016.

For DHS, only information on baseline residential addresses was available. Walkability measures could not be computed for $3 \%$ at baseline, $16 \%$ at follow-up 1 and $3.6 \%$ at follow-up 2, because addresses could not be geocoded.

\section{Outcomes}

Prevalent and incident T2D were defined by self-report of physician-diagnosed diabetes or antidiabetic drug intake in the 7 days prior to the examination.

\section{Covariates}

Number of years of education was derived from a standardized questionnaire. Years of education were classified based on the International Standard Classification of Education 1997 [29], including school years and years of vocational education in the total number of years with the categories: $9 / 10$ years, $12 / 13$ years, $14-17$ years and 18 and more years. Eleven years is not included, since in Germany one can finish school after 9 or 10 years and then start vocational education or unskilled working, or one can finish after 12 or 13 years, which qualifies for university entry. Baseline BMI was derived from measured weight and height using comparable protocols in the five cohort studies. Self-reported hours per week of practicing sports were categorized with the following categories: more than $2 \mathrm{~h}, 1-2 \mathrm{~h}$, less than $1 \mathrm{~h}$ of sports per week and practicing no sports.

\section{Statistical analysis}

Sample characteristics were reported as means with standard deviation (SD) or medians with interquartile range (IQR) according to the distribution of the data or as frequencies (percentages) for categorical variables.

For associations between walkability measures and prevalent and incident $\mathrm{T} 2 \mathrm{D}$, we estimated risk ratios (RR) using modified Poisson regression with robust error variance [30, 31]. For better interpretability and comparability, we present estimates for z-standardized walkability measures.

In sensitivity analysis, we examined the association between walkability measures and T2D incidence in a sub-sample of participants whose addresses were the same during each of the follow-up assessments (hereafter 'non-movers'). Additionally, we examined the association between walkability measures and T2D incidence in a sub-sample excluding all participants aged less than 30 years at baseline in order to exclude potential type 1 diabetes cases from the analysis. Finally, we also conducted an analysis in which we used the T2D status at the last follow-up as outcome in order to reduce the time gap between walkability assessment and T2D prevalence assessment.

We adjusted all models for sex, age at baseline, education, and cohort. Additionally, we examined if the associations differed in certain age groups (20-40 years, 41-60 years and over 60 years). Moreover, we adjusted the associations for practicing sports. All analyses were performed with SAS V.9.4 [32].

\section{Results}

Of the baseline 16,008 participants, 1256 (7.8\%) had prevalent T2D. During the follow up over a mean of 9.2 years (SD: 3.5, minimum: 1.6, maximum: 14.8 years), further 1032 participants developed T2D. Participants with prevalent or incident T2D were more often male, older, and had fewer years of education when compared to participants without T2D. Additionally, participants with T2D lived in areas with slightly more transit stations and POI when compared to participants without T2D. Impedance at the participant's residential addresses was comparable in participants with and without T2D (Table 1). All estimates for the association between the walkability measures and T2D prevalence and incidence were within $7 \%$ of $\mathrm{RR}=1$ per $1 \mathrm{SD}$, with $95 \%$ confidence intervals including 1 (Table 2), showing no association between walkability measures and T2D. Given the large sample size, the $95 \%$ confidence intervals were narrow, indicating high precision of our estimates. 
Table 1 Characteristics of participants

\begin{tabular}{|c|c|c|c|c|c|}
\hline & & \multicolumn{2}{|c|}{$\begin{array}{l}\text { Sample for examining prevalent T2D } \\
(N=16,008)\end{array}$} & \multicolumn{2}{|c|}{$\begin{array}{l}\text { Sample for examining incident T2D } \\
(N=12,105)\end{array}$} \\
\hline & & $\begin{array}{l}\text { Prevalent T2D at baseline } \\
(N=1256)\end{array}$ & $\begin{array}{l}\text { No T2D at baseline } \\
(N=14,752)\end{array}$ & $\begin{array}{l}\text { Incident T2D during follow-up } \\
(N=1032)\end{array}$ & $\begin{array}{l}\text { No T2D during follow-up } \\
(N=11,073)\end{array}$ \\
\hline Male & n (\%) & $707(56.3)$ & $7231(49.0)$ & $588(57.0)$ & $5271(47.6)$ \\
\hline Age at baseline & Mean (SD) & $63.9(9.8)$ & $53.5(13.9)$ & $59.0(9.9)$ & $52.9(13.4)$ \\
\hline \multicolumn{6}{|l|}{ Education (years) } \\
\hline $9-10$ & n (\%) & $260(20.7)$ & $1598(10.8)$ & $112(10.9)$ & $1012(9.1)$ \\
\hline $12-13$ & n (\%) & $613(48.8)$ & $7722(52.3)$ & $575(55.7)$ & $5731(51.8)$ \\
\hline $14-17$ & n (\%) & $218(17.4)$ & 2786 (18.9) & $189(18.3)$ & 2168 (19.6) \\
\hline$\geq 18$ & n (\%) & $165(13.1)$ & $2646(17.9)$ & $156(15.1)$ & $2162(19.5)$ \\
\hline \multicolumn{6}{|l|}{ Walkability measures } \\
\hline Impedance & Mean (SD) & 1623.9 (307.4) & $1616.1(289.9)$ & $1615.3(267.1)$ & 1616.5 (288.6) \\
\hline Transit stations & Median (Q1-Q3) & $4.6(2.7-6.9)$ & $4.3(2.3-6.9)$ & $4.7(2.5-7.1)$ & $4.3(2.4-6.9)$ \\
\hline Points of interest & Median (Q1-Q3) & $5.0(2.3-10.1)$ & $4.8(2.1-9.5)$ & $5.3(2.6-9.8)$ & $4.8(2.2-9.0)$ \\
\hline \multicolumn{6}{|l|}{ Risk factors for T2D } \\
\hline \multicolumn{6}{|l|}{ Practicing sports } \\
\hline More than $2 \mathrm{~h} /$ week & n (\%) & $196(15.7)$ & $3470(23.7)$ & $200(19.5)$ & $2804(25.5)$ \\
\hline 1-2 h/week & n (\%) & $144(11.5)$ & $2767(18.8)$ & $156(15.2)$ & 2169 (19.7) \\
\hline Less than $1 \mathrm{~h} /$ week & n (\%) & $97(7.7)$ & $1673(11.4)$ & $111(10.8)$ & $1257(11.4)$ \\
\hline No sports & n (\%) & $814(65.1)$ & $6758(46.1)$ & $560(54.5)$ & $4783(43.4)$ \\
\hline BMI at baseline & Mean (SD), n & $30.5(5.3), 1252$ & $27.3(4.6), 14,684$ & $30.6(4.8), 1024$ & $27.0(4.4), 11,042$ \\
\hline
\end{tabular}

T2D Type 2 diabetes, SD Standard deviation, Q Quartile, BMI Body mass index

Table 2 Association between T2D and walkability

\begin{tabular}{|c|c|c|c|c|c|c|c|c|}
\hline & \multirow{2}{*}{\multicolumn{2}{|c|}{$\begin{array}{l}\text { Prevalent T2D } \\
(N=16,008)\end{array}$}} & \multirow{2}{*}{\multicolumn{2}{|c|}{$\begin{array}{l}\text { Incident T2D } \\
(N=12,105)\end{array}$}} & \multicolumn{4}{|c|}{ Sensitivity analysis } \\
\hline & & & & & \multicolumn{2}{|c|}{$\begin{array}{l}\text { Incident T2D non-movers } \\
(N=5901)\end{array}$} & \multicolumn{2}{|c|}{$\begin{array}{l}\text { Incident T2D age } \geq 30 \text { years at baseline } \\
(N=11,416)\end{array}$} \\
\hline & $\mathrm{RR}$ & $95 \% \mathrm{Cl}$ & $\mathrm{RR}$ & $95 \% \mathrm{Cl}$ & $\mathrm{RR}$ & $95 \% \mathrm{Cl}$ & $\mathrm{RR}$ & $95 \% \mathrm{Cl}$ \\
\hline \multicolumn{9}{|l|}{ Impedance } \\
\hline Crude & 1.02 & $0.97,1.08$ & 1.00 & $0.94,1.05$ & 0.99 & $0.92,1.07$ & 1.00 & $0.95,1.07$ \\
\hline Adjusted & 1.03 & $0.97,1.09$ & 1.00 & $0.94,1.06$ & 1.02 & $0.95,1.11$ & 0.99 & $0.93,1.06$ \\
\hline \multicolumn{9}{|c|}{ Transit stations } \\
\hline Crude & 1.05 & $0.99,1.10$ & 1.07 & $1.01,1.13$ & 1.09 & $1.00,1.17$ & 1.05 & $0.99,1.11$ \\
\hline Adjusted & 1.03 & $0.97,1.10$ & 1.05 & $0.98,1.13$ & 1.05 & $0.97,1.15$ & 1.06 & $0.98,1.14$ \\
\hline \multicolumn{9}{|c|}{ Points of interest } \\
\hline Crude & 1.04 & $0.99,1.09$ & 1.06 & $0.99,1.12$ & 1.02 & $0.95,1.10$ & 1.05 & $0.99,1.11$ \\
\hline Adjusted & 1.05 & $0.99,1.11$ & 1.01 & $0.95,1.08$ & 0.98 & $0.91,1.07$ & 1.01 & $0.95,1.08$ \\
\hline
\end{tabular}

Adjusted models are controlled for sex, age at baseline, education, and cohort. T2D Type 2 diabetes, RR Relative risk, Cl Confidence interval. RR are from modified Poisson regression models and reported per 1 standard deviation of walkability measures. RR over 1 indicate higher risk of T2D in areas with more transit stations and POI (indicators of better walkability). RR over 1 indicate higher risk of T2D in areas with higher impedance (indicator of poorer walkability)

For prevalent T2D analysis ( $N=16,008)$ : standard deviation (SD) impedance: 291.3, POI: 4.8, transit stations: 4.4

For incident T2D analysis ( $N=12,105)$ : SD impedance: 286.8, POI: 7.1, transit stations: 5.3

For incident T2D non-movers $(\mathrm{N}=5901)$ SD impedance $=284.6$, POI: 6.7 , transit stations: 4.9

For incident $T 2 D$ age $\geq 30$ years at baseline $(\mathrm{N}=11,416)$ SD impedance: 282.5 , POI: 7.5 , transit stations: 4.1 
Results of a sensitivity analysis assessing the association between walkability and the most recent follow-up status on T2D were qualitatively the same (for impedance RR 0.99; 95\% CI 0.95, 1.04; POI: 1.02; 0.98, 1.06; transit stations: $1.07 ; 1.01,1.13, n=9441)$.

These result of no association between walkability and T2D was confirmed by further analysis, were we stratified for age group and adjusted for practicing sports (See Additional file 1: Table S1 and S2).

\section{Discussion}

In the present study we analysed data from 16,008 participants from five German cohort studies. Our results point towards a lack of association between walkability and T2D in the studied environments.

Walkability was measured in different ways in different studies, which hinders comparability of our results with the current literature. However, most studies showed a lower T2D risk with better walkability. Pooled effects in a recent review would translate into a $20 \%$ T2D risk reduction with better walkability [12].

Most studies that found associations between better walkability and decreased T2D risk used objective composite scores including measures we did not take into account, for example residential, population and intersection density, and land use mix [33-36]. While these studies combined different walkability measures into an index score and found association with diabetes, we aimed to analyze the contribution of single measures.

Christine and colleagues (2015) found associations for better subjective walkability measures, which we did not consider, and decreased T2D risk [37]. We focused on the classical and rather gross features of walkability that arose from urban planning. We did not consider fine features, such as bike path, pedestrian crossings, or avenues, nor did we consider green spaces and parks. Moreover, we did not include aesthetics and perceived safety. These walkability measures could be more important in determining especially leisure time related walking than single gross features of walkability [38]. Therefore, these measures would also be more important regarding T2D risks. Paquet et al. (2014) reported a 12\% reduced risk with increasing walkability in a smaller sample and less years of follow-up when compared to our population [39]. The study took place in Adelaide, South Australia, which is different from European cities in terms of built environment attributes [14, 39].

The density and diversity of European cities and their city centres may have a greater potential to promote physical activity for transport and leisure time as when compared to Australia, where the structures of the cities are more car-oriented and more heterogeneous regarding walkability [38]. The homogeneity of the walkability measures in our study regions could explain the observed lack of association. Additionally, Paquet et al. (2014) analysed diabetes and prediabetes as one clinical endpoint, which hinders comparability with our results [39].

However, not all studies have found associations between walkability and T2D. Müller-Riemenschneider and colleagues (2013) reported that after adjustment for individual SES, the previously existing positive effect of walkability on incident T2D disappeared [40]. Nevertheless, the estimates still pointed towards a decreased T2D risk with better walkability.

The only other study we know about that was conducted in the European context found no association between walkability and diabetes in the city of Stockholm [16]. This study only included participants who were taking medication because of their disease. On the one hand, the exclusion of participants with T2D not taking medication could have underestimated the effect [41]. On the other hand, these results could also indicate the homogeneity of walkability measures in European cities, as indicated by our study.

Various specific factors could explain the null effect for T2D with more POI and transit stations in our study. First, POI included restaurants and fast food chains. Eating out of home is associated with obesity and could by increasing the T2D risk, diminish any positive effect of walkability [42]. Regarding transit stations, high cost of public transport, low frequency routes and transport that serves only few routes could hinder transport related walking and promote car-dependence, even though public transport is available. Consequently, this would result in a null effect, as observed in our study. Additionally, some environmental factors are associated with high urbanity and with high walkability. These factors, such as air pollution, could at the same time increase the risk of T2D and hence diminish the positive effect walkability has on T2D, which would result in no observable effect [43]. Regarding impedance, we did not observe any associations with T2D. This may be due to different ways of how impedance could work. People living in areas with high impedance could be less likely to walk, which would lead to lower activity and higher T2D risk. However, when it is inconvenient to use a car, activity could increase and T2D risk would decrease. Areas which have different road networks, parking availability and parking cost could be different in the effect impedance has on people's walking and cycling behavior and hence on their T2D risk. A river as a geographical barrier could hinder transport related walking. At the same time, it could increase leisure time related walking, jogging or cycling for recreation.

In our recent cross-sectional analysis on a similar pooled study population, better walkability was associated with lower BMI, but the observed associations were 
rather weak [17]. The already weak positive effect of walkability via increased walking and cycling on BMI may simply not be strong enough to have any observable effects on T2D, which lies one step further down the causal chain. Additionally, when we stratified the associations by cohort, we observed that the association between better walkability and lower BMI was not consistent among the cohorts. As described above, even though walkability could contribute to increased walking and cycling behaviour and therefor to decreased BMI (even though to a very low extent), other factors related to walkability could diminish possible positive effects of walkability on health outcomes resulting from obesity and hence, resulting in a lack of association.

Some limitations need to be considered. First, diabetes was based on self-report. However, results of several studies indicate that for diabetes the validity of selfreports is generally high [44, 45]. Moreover, we could not adjust for residential self-selection and only adjusted for education as one part of individual SES, but not for income, occupation, or area level SES.

Participants, who choose to live in a walkable area, might be more health-conscious, have a higher income and live a healthier lifestyle than people, who cannot afford living in the city centre, where rents, but also connectivity as well as the amount of transit stations and POI might be higher. Hence, regardless of walking and cycling for recreation and transport, those people would have lower T2D risk than participants with low socioeconomic status, who are living in low walkable areas. Although we adjusted for education in our analysis, education alone does not reflect socioeconomic status, residential self-selection, and general health behaviour. Income level and social status influence T2D risk and walkability. However, we did not observe any association between walkability and T2D risk in crude and adjusted models and the adjustment for education only yielded minor changes in the association when compared to the crude association.

The strongest limitation is that the walkability measures were compiled for a much later time period then baseline data, which could have resulted in misclassification of walkability measures. However, we could show that the analysis based on the last follow-up status of T2D as outcome produced similar results. One can assume that if there is some fluctuation in for example points of interest over time, than still it occurs mostly within the same areas, minimizing the risk of misclassification. Furthermore, we did not include other important aspects of walkability, such as perceived aesthetics, safety, residential density, and presence of green spaces and parks. Lastly, there are some limitations of our walkability measures. Variety of POI was not explicitly taken into account and bus and tram stops might be very different in quality, according to high or low frequency routes. While impedance indicates lack of walkable streets, it can include rivers and forests which might be on the other hand highly attractive for walking.

Despite these limitations, the study has several strengths. Different regions and cities in Germany were taken into account. With pooling data from five cohorts, we were able to cover almost an entire European country. Most previous studies included single cities in a country and were mostly conducted in North America and Australia. This study is one of the first studies that examined the association between walkability and T2D in Europe.

\section{Conclusion}

Overall, the results of our study rather indicate a lack of association between walkability and T2D risk in German settings. This might be due to the homogeneity of the walkability measures in the studied population.

\section{Supplementary information}

Supplementary information accompanies this paper at https://doi.org/10. 1186/s12902-019-0485-x.

Additional file 1: Table S1. Association between walkability and T2D by age group. Table S2. Association between walkability and T2D adjusted for practicing sports.

\section{Abbreviations}

BMI: Body Mass Index; Cl: Confidence Interval; OSM: OpenStreetMap; POI: Points of interest; RR: Relative Risk; SD: Standard deviation; T2D: Type 2 Diabetes

\section{Acknowledgements}

We thank all participants of the cohort studies and all members of the study teams who participated in the recruitment, data collection, data management, and analysis.

\section{Author's contributions}

SH planned the study and reviewed the manuscript. NK conducted the statistical analysis and wrote the manuscript. GR and MPS planned the study, devised, and created the walkability measures. DT assigned the walkability measures to the CARLA participants. AK and KHG planned and coordinated the CARLA study and devised the walkability study. US, NB, KW, WM, AP, CK, and SA provided data and reviewed the manuscript. GR, MPS, AK, KHG, RM,

$R S, S M$, reviewed the manuscript and contributed to the discussion. GR contributed to the methods and discussion part. AW advised on the statistical analysis. All authors read and approved the final manuscript.

\section{Funding}

This work was supported by the Competence Network Diabetes Mellitus of the German Federal Ministry of Education and Research (BMBF, grant 01Gl110C) and the Competence Network Obesity (BMBF, grant 01Gl1121B). The Cardiovascular Disease, Living and Ageing in Halle (CARLA) Study was supported by a grant from the Deutsche Forschungsgemeinschaft as part of the Collaborative Research Center 598 "Heart failure in the elderly-cellular mechanisms and therapy" at the Medical Faculty of the Martin-LutherUniversity Halle-Wittenberg, by a grant of the Wilhelm-Roux Programme of the Martin-Luther-University Halle-Wittenberg; by the Ministry of Education and Cultural Affairs of Saxony-Anhalt, and by the Federal Employment Office. The Study of Health in Pomerania (SHIP) is part of the Community Medicine Research net (http://www.community-medicine.de) at the University of Greifswald, Germany. Funding was provided by grants from the German Federal Ministry of Education and Research (BMBF, grant 01ZZ0403); the Ministry for Education, Research, and Cultural Affairs; and the Ministry for 
Social Affairs of the Federal State of Mecklenburg-West Pomerania. The Heinz Nixdorf Recall Study (RECALL) was generously supported by the Heinz Nixdorf Foundation (Germany). The study is also supported by the German Ministry of Education and Science. The KORA research platform (KORA, Cooperative Health Research in the Region of Augsburg) was initiated and financed by the Helmholtz Zentrum München-German Research Center for Environmental Health, which is funded by the German Federal Ministry of Education and Research and by the State of Bavaria. Furthermore, KORA research was supported within the Munich Center of Health Sciences (MCHealth), Ludwig-Maximilians-Universität München, as part of LMUinnovativ. The Dortmund Health Study (DHS) was supported by unrestricted grants to the University of Münster from the German Migraine and Headache Society and a consortium formed with equal shares by Allmiral, Astra-Zeneca, BerlinChemie, Boehringer Ingelheim Pharma, Boots Healthcare, GlaxoSmithKline, Janssen Cilag, McNeil Pharmaceuticals, MSD Sharp \& Dohme, and Pfizer. Gavin Rudge and Mark Patrick Sheldon were funded by the National Institute for Health Research (NIHR) Collaborations for Leadership in Applied Health Research and Care the West Midlands. The views expressed are those of the author(s) and not necessarily those of the NHS, the NIHR or the Department of Health.

The funders had no role in conceptualization of the study, data collection, data analysis and writing the manuscript.

\section{Availability of data and materials}

The datasets generated and/or analysed during the current study are not publicly available due to data privacy but are available from the corresponding author on reasonable request.

\section{Ethics approval and consent to participate}

The studies have been conducted according to the principles of the Declaration of Helsinki and have been approved by local ethics committees and written informed consent has been obtained. There were no participants under 16 years old and hence no written informed consent from a parent or guardian was necessary.

KORA (Helmholtz Zentrum München): Ethics committee of the Bavarian Medical Association and the Bavarian commissioner for data protection and privacy (approval number: 06068).

CARLA (Martin-Luther-University): Ethics committee of the Medical Faculty of Martin-Luther-University and the state data privacy commissioner of SaxonyAnhalt (approval number: 164/12.10.05/1).

RECALL (University Clinics Essen): Ethics committee of the Medical Faculty of the University Duisburg-Essen (approval number: 99-69-1200).

DHS (University of Münster): Ethics committee of the University of Münster and the Westphalian Chamber of Physicians in Münster (approval number: 3VIIBerger).

SHIP (Ernst-Moritz-Arndt University Greifswald): Ethics committee of the Medical Faculty of the Ernst-Moritz-Arndt University Greifswald (approval number: III UV 73/01/BB 39/09).

\section{Consent for publication}

Not applicable.

\section{Competing interests}

The authors declare that they have no competing interests.

\section{Author details}

${ }^{1}$ Institute of Medical Epidemiology, Biometrics and Informatics, Martin-Luther-University Halle-Wittenberg, Magdeburger Straße 8, 06112 Halle (Saale), Germany. ${ }^{2}$ German Center for Diabetes Research (Deutsches Zentrum für Diabetesforschung DZD), Ingolstädter Landstraße 1, 85764 Neuherberg, Germany. ${ }^{3}$ Centre for Urban Epidemiology, University Clinics Essen, Hufelandstr. 55, 45122 Essen, Germany. ${ }^{4}$ Institute of Applied Health Research, University of Birmingham, Edgbaston, Birmingham B15 2T, UK. ${ }^{5}$ German Cancer Research Center DKFZ (Deutsches Krebsforschungszentrum) Heidelberg, Im Neuenheimer Feld 280, 69120 Heidelberg, Germany. ${ }^{6}$ Institute of Geosciences and Geography, Martin-Luther-University Halle-Wittenberg, 06099 Halle (Saale), Germany. ${ }^{7}$ Institute for Community Medicine, University Medicine Greifswald, Ellernholzstr. 1-2, 17487 Greifswald, Germany. ${ }^{8}$ Institute of Epidemiology, Helmholtz Zentrum München, Ingolstädter Landstr. 1, 85764 Neuherberg, Germany. ${ }^{9}$ Institute of Health Economics and Health Care Management, Helmholtz Zentrum München, Ingolstädter Landstraße 1,
85764 Neuherberg, Germany. ${ }^{10}$ Institute of Epidemiology and Social Medicine, University of Münster, Albert-Schweitzer-Campus 1, 48149 Münster, Germany.

Received: 16 September 2019 Accepted: 27 December 2019

Published online: 13 January 2020

\section{References}

1. Forouzanfar MH, Afshin A, Alexander LT, Anderson HR, Bhutta ZA, Biryukov S, et al. Global, regional, and national comparative risk assessment of 79 behavioural, environmental and occupational, and metabolic risks or clusters of risks, 1990-2015: a systematic analysis for the global burden of disease study 2015. Lancet. 2016;388(10053):1659-724.

2. Bassett DR, Pucher J, Buehler R, Thompson DL, Crouter SE. Walking, cycling, and obesity rates in Europe, North America, and Australia. J Phys Act Health. 2008;5(6):795-814

3. Beaglehole R, Bonita R, Horton R, Adams C, Alleyne G, Asaria P, et al. Priority actions for the non-communicable disease crisis. Lancet. 2011;377(9775): 1438-47.

4. Richard L, Gauvin L, Raine K. Ecological models revisited: their uses and evolution in health promotion over two decades. Annu Rev Public Health. 2011;32:307-26.

5. Althoff T, Hicks JL, King AC, Delp SL, Leskovec J. Large-scale physical activity data reveal worldwide activity inequality. Nature. 2017;547(7663):336.

6. Cerin E, Nathan A, Van Cauwenberg J, Barnett DW, Barnett A. The neighbourhood physical environment and active travel in older adults: a systematic review and meta-analysis. Int J Behav Nutr Phys Act. 2017;14(1):15.

7. Smith M, Hosking J, Woodward A, Witten K, MacMillan A, Field A, et al. Systematic literature review of built environment effects on physical activity and active transport-an update and new findings on health equity. Int $J$ Behav Nutr Phys Act. 2017;14(1):158.

8. Van Holle V, Deforche B, Van Cauwenberg J, Goubert L, Maes L, Van de Weghe $\mathrm{N}$, et al. Relationship between the physical environment and different domains of physical activity in European adults: a systematic review. BMC Public Health. 2012;12(1):807.

9. Garfinkel-Castro A, Kim K, Hamidi S, Ewing R. Obesity and the built environment at different urban scales: examining the literature. Nutr Rev. 2017;75(suppl_1):51-61.

10. Martin A, Ogilvie D, Suhrcke M. Evaluating causal relationships between urban built environment characteristics and obesity: a methodological review of observational studies. Int J Behav Nutr Phys Act. 2014;11(1):142.

11. Oliver M, Mavoa S, Badland H, Parker K, Donovan P, Kearns RA, et al. Associations between the neighbourhood built environment and out of school physical activity and active travel: an examination from the kids in the City study. Health Place. 2015;36:57-64.

12. Den Braver N, Lakerveld J, Rutters F, Schoonmade L, Brug J, Beulens J. Built environmental characteristics and diabetes: a systematic review and metaanalysis. BMC Med. 2018;16(1):12

13. Chandrabose M, Rachele J, Gunn L, Kavanagh A, Owen N, Turrell G, et al. Built environment and cardio-metabolic health: systematic review and meta-analysis of longitudinal studies. Obes Rev. 2019;20(1):41-54.

14. Van Dyck D, Cerin E, Conway TL, De Bourdeaudhuij I, Owen N, Kerr J, et al. Perceived neighborhood environmental attributes associated with adults' transport-related walking and cycling: findings from the USA, Australia and Belgium. Int J Behav Nutr Phys Act. 2012;9(1):70.

15. Christiansen LB, Cerin E, Badland H, Kerr J, Davey R, Troelsen J, et al. International comparisons of the associations between objective measures of the built environment and transport-related walking and cycling: IPEN adult study. J Transp Health. 2016;3(4):467-78.

16. Sundquist K, Eriksson U, Mezuk B, Ohlsson H. Neighborhood walkability, deprivation and incidence of type 2 diabetes: a population-based study on 512,061 Swedish adults. Health Place. 2015;31:24-30.

17. Kartschmit NSR, Sheldon MP, Moebus S, Greiser KH, Hartwig S. Walkability, physical activity and body mass index: Analyses of cross-sectional data of 5 German cohorts. Bremen: 13. Jahrestagung der Deutschen Gesellschaft für Epidemiologie; 2018.

18. Lamb KE, White SR. Categorisation of built environment characteristics: the trouble with tertiles. Int J Behav Nutr Phys Act. 2015;12(1):19.

19. Brown BB, Yamada I, Smith KR, Zick CD, Kowaleski-Jones L, Fan JX. Mixed land use and walkability: variations in land use measures and relationships with BMI, overweight, and obesity. Health Place. 2009;15(4):1130-41. 
20. Brownson RC, Hoehner CM, Day K, Forsyth A, Sallis JF. Measuring the built environment for physical activity: state of the science. Am J Prev Med. 2009; 36(4):S99-S123 e12.

21. Berger K. DHS: the Dortmund health study. Bundesgesundheitsblatt Gesundheitsforschung Gesundheitsschutz. 2012;55(6-7):816-21.

22. Erbel R, Eisele L, Moebus S, Dragano N, Möhlenkamp S, Bauer M, et al. Die Heinz Nixdorf Recall Studie. Bundesgesundheitsblatt-GesundheitsforschungGesundheitsschutz. 2012;55(6-7):809-15.

23. Greiser KH, Kluttig A, Schumann B, Kors JA, Swenne CA, Kuss O, et al. Cardiovascular disease, risk factors and heart rate variability in the elderly general population: design and objectives of the CARdiovascular disease, living and ageing in Halle (CARLA) study. BMC Cardiovasc Disord. 2005;5(1):33.

24. Greiser KH, Kluttig A, Schumann B, Swenne CA, Kors JA, Kuss O, et al. Cardiovascular diseases, risk factors and short-term heart rate variability in an elderly general population: the CARLA study 2002-2006. Eur J Epidemiol. 2009;24(3):123

25. Holle R, Happich M, Löwel H, Wichmann H-E, Group nftMKS. KORA-a research platform for population based health research. Das Gesundheitswesen. 2005:67(S 01):19-25.

26. John U, Hensel E, Lüdemann J, Piek M, Sauer S, Adam C, et al. Study of health in Pomerania (SHIP): a health examination survey in an east German region: objectives and design. Sozial-und Präventivmedizin. 2001;46(3):186-94.

27. Völzke H, Alte D, Schmidt CO, Radke D, Lorbeer R, Friedrich N, et al. Cohort profile: the study of health in Pomerania. Int J Epidemiol. 2010;40(2):294-307.

28. Lewis $D$, Mateos P, Longley P. Choice and the composition of general practice patient registries; 2009.

29. Schneider SL. Applying the ISCED-97 to the German educational qualifications. In: The international standard classification of education, Edited by: Schneider SL. Mannheim: MZES; 2008. p. 77-102.

30. Spiegelman D, Hertzmark E. Easy SAS calculations for risk or prevalence ratios and differences. Am J Epidemiol. 2005;162(3):199-200.

31. Zou G. A modified poisson regression approach to prospective studies with binary data. Am J Epidemiol. 2004;159(7):702-6.

32. SAS Institute 2017. Cary, North Carolina, USA.

33. Auchincloss AH, Roux AVD, Mujahid MS, Shen M, Bertoni AG, Carnethon MR. Neighborhood resources for physical activity and healthy foods and incidence of type 2 diabetes mellitus: the multi-ethnic study of atherosclerosis. Arch Intern Med. 2009;169(18):1698-704.

34. Booth GL, Creatore MI, Moineddin R, Gozdyra P, Weyman JT, Matheson Fl, et al. Unwalkable neighborhoods, poverty, and the risk of diabetes among recent immigrants to Canada compared with long-term residents. Diabetes Care. 2013;36(2):302-8

35. Glazier RH, Creatore MI, Weyman JT, Fazli G, Matheson Fl, Gozdyra P, et al. Density, destinations or both? A comparison of measures of walkability in relation to transportation behaviors, obesity and diabetes in Toronto, Canada. PLoS One. 2014;9(1):e85295.

36. Creatore MI, Glazier RH, Moineddin R, Fazli GS, Johns A, Gozdyra P, et al. Association of neighborhood walkability with change in overweight, obesity, and diabetes. Jama. 2016:315(20):2211-20.

37. Christine PJ, Auchincloss AH, Bertoni AG, Carnethon MR, Sánchez BN, Moore $\mathrm{K}$, et al. Longitudinal associations between neighborhood physical and social environments and incident type 2 diabetes mellitus: the multi-ethnic study of atherosclerosis (MESA). JAMA Intern Med. 2015;175(8):1311-20.

38. Tran MC, Schmidt JA. Walkability aus Sicht der Stadt-und Verkehrsplanung. In: Buksch J, Schneider S, editors. Walkability. Ein Handbuch zur Bewegungsförderung in der Kommune. Bern: Verlag Hans Huber; 2014.

39. Paquet C, Coffee NT, Haren MT, Howard NJ, Adams RJ, Taylor AW, et al. Food environment, walkability, and public open spaces are associated with incident development of cardio-metabolic risk factors in a biomedical cohort. Health Place. 2014;28:173-6.

40. Müller-Riemenschneider F, Pereira G, Villanueva K, Christian H, Knuiman M, Giles-Corti B, et al. Neighborhood walkability and cardiometabolic risk factors in Australian adults: an observational study. BMC Public Health. 2013; 13(1):755.

41. Dendup T, Feng $X$, Clingan S, Astell-Burt T. Environmental risk factors for developing type 2 diabetes mellitus: a systematic review. Int J Environ Res Public Health. 2018;15(1):78.

42. Naska A, Orfanos P, Trichopoulou A, May A, Overvad K, Jakobsen MU, et al. Eating out, weight and weight gain. A cross-sectional and prospective analysis in the context of the EPIC-PANACEA study. Int J Obes (Lond). 2011; 35(3):416.
43. Eze IC, Hemkens LG, Bucher HC, Hoffmann B, Schindler C, Künzli N, et al. Association between ambient air pollution and diabetes mellitus in Europe and North America: systematic review and meta-analysis. Environ Health Perspect. 2015;123(5):381-9.

44. Margolis KL, Qi L, Brzyski R, Bonds DE, Howard BV, Kempainen S, et al. Validity of diabetes self-reports in the Women's Health Initiative: comparison with medication inventories and fasting glucose measurements. Clin Trials. 2008;5(3):240-7.

45. Molenaar EA, Ameijden EJV, Grobbee DE, Numans ME. Comparison of routine care self-reported and biometrical data on hypertension and diabetes: results of the Utrecht health project. Eur J Publ Health. 2006;17(2): 199-205.

\section{Publisher's Note}

Springer Nature remains neutral with regard to jurisdictional claims in published maps and institutional affiliations.
Ready to submit your research? Choose BMC and benefit from:

- fast, convenient online submission

- thorough peer review by experienced researchers in your field

- rapid publication on acceptance

- support for research data, including large and complex data types

- gold Open Access which fosters wider collaboration and increased citations

- maximum visibility for your research: over $100 \mathrm{M}$ website views per year

At BMC, research is always in progress.

Learn more biomedcentral.com/submissions 